\title{
EPISTEMOLOGIA DA PRODUÇÃO DO ESPAÇO LEFEBVRIANO
}

Epistemology of the production of the lefebvriano space

Epistemología espacio de producción lefebvristas

\section{Elisabete Ferreira da Silveira Guilherme*}

* Mestranda do Programa de Pós-Graduação e Pesquisa em Geografia, Universidade Federal do Rio Grande do Norte, Natal/RN, Brasil.

*Correspondência: UFRN. CCHLA. Departamento de Geografia-Programa de Pós-Graduação e Pesquisa em Geografia. Campus Universitário s/n - Lagoa Nova - Natal, Rio Grande do Norte. Brasil. CEP:59.078-970. Email:ppge.ufrn@gmail.com.

\section{RESUMO}

A epistemologia é a ciência relacionada à prática do conhecimento, para qual o método é fundamental ao conhecimento científico. Este artigo lança-se sobre a problemática da epistemologia da teoria da produção do espaço e seu rebatimento filosófico nas Ciências Sociais. Objetivamente, buscamos traçar notas acerca da epistemologia da teoria da produção do espaço de Henri Lefebvre com relevo a sua significância à Geografia. Para tanto, recorreremos a leitura da sua obra de mesmo nome La producción del espacio, bem como revisão da literatura pertinente e de informações já publicadas e disponíveis em impressos ou meio eletrônico acerca da episteme, do conceito de espaço e de sua produção capitalista, do urbano e da própria teoria de Lefebvre. Em síntese, a teoria discutida não se resume apenas a uma obra, se insere numa produção sobre a cidade, o espaço e o urbano que carrega consigo as marcas da observação e interpretação do seu tempo. Seu autor buscou, através do seu método e métodos de procedimento, construir um projeto de conhecimento simultaneamente descritivo, analítico e global que redundasse numa teoria sobre a produção do espaço urbano.

Palavras-chave: Epistemologia. Produção do Espaço. Henri Lefebvre.

\section{ABSTRACT}

Epistemology is the science related to the practice of knowledge, for which the method is fundamental to scientific knowledge. This article focuses on the problematic of the epistemology of space production theory and its philosophical importance in Social Sciences. Objectively, we seek to draw notes on the epistemology of Henri Lefebvre's space production theory with emphasis on its significance to Geography. To do so, we will turn to the reading of his work of the same name La producción del espacio, as well as a review of relevant literature and information already published and available in print or electronic media about episteme, the concept of space and its capitalist production, of the urban and of Lefebvre's own theory. In short, the theory discussed it is part of a production about the city, the space and the urban that carries with it the marks of observation and interpretation of its time. Its author sought, through his method and methods of procedure, to construct a simultaneously descriptive, analytical and global knowledge project that would result in a theory about an urban space production.

Keywords: Epistemology. Production of the Space. Henri Lefebvre.

\section{RESUMEN}

La epistemología es la ciencia relacionada con la práctica de los conocimientos, a la que el método es fundamental para el conocimiento científico. Este artículo se ocupa de la epistemología de la teoría de la producción del espacio y su rebote filosófico en Ciencias Sociales. Objetivamente, buscamos dibujar notas sobre la epistemología de la teoría de la producción de Henri Lefebvre espacio con elevado su importancia a la Geografía. 
Por lo tanto, vamos a utilizar la lectura de su obra del mismo nombre de La Producción del Espacio, y revisión de la literatura y la información ya publicada y disponible en forma impresa o electrónica, sobre la episteme, el concepto del espacio y su producción capitalista, lo urbano y la propia teoría de Lefebvre. En resumen, la teoría discutida es parte de una producción de la ciudad y el espacio que lleva las marcas de la observación e interpretación de su tiempo. Su autor buscó, a través de su método y métodos de procedimiento, la construción de un proyecto de conocimiento descriptivo, analítico y global que redundasse una teoría de la producción del espacio urbano.

Descriptores: Epistemología. Producción del Espacio. Henri Lefebvre.

\section{INTRODUÇÃO}

A epistemologia, palavra que vem do grego, trata da teoria da ciência, cujo objeto de estudo é a produção e validação do conhecimento científico. Sua associação com a gnosiologia, a qual cuida da teoria do conhecimento com foco a determinar o alcance, a natureza e a origem do conhecimento, constituem-na como a doutrina dos fundamentos e dos métodos do conhecimento científico, ligando-a, desse modo, à filosofia da ciência, conforme Conceito...(2013). Para o conhecimento científico, Sposito (2004) sugere ser importante considerar as seguintes perguntas: Como fazer ciência, referindo-se a importância do método; Por quê, relacionada às razões históricas do assunto que se discute; o Quando, para possibilitar a contextualização, no tempo, das ideias e autores, bem como as matrizes filosóficas; e Onde os fatos ocorreram.

Carlos (2016), discorrendo sobre a produção do espaço urbano, contempla a relação dialética entre sociedade/espaço sob a orientação de um pensamento geográfico segundo o qual se deve recorrer à Filosofia como condição necessária para a compreensão do mundo, onde a Geografia, como saber, demandaria o reconhecimento da fundamentação filosófica sobre a qual se fundam as Ciências Sociais, a saber: a atitude crítica e o comportamento radical, este último no sentido de exigir o desvendamento da sociedade em que vivemos imersa em contradições que eclodem em conflitos, revelando a necessidade de uma crítica ao capital e às sempre renovadas 'formas de realização do lucro', da alienação e da submissão do indivíduo ao plano da acumulação [de bens], ao empobrecimento humano ante a orientação das suas necessidades a desejos saciados pelo consumo.

$\mathrm{Na}$ continuidade do seu pensamento, Carlos (ibidem, p. 56) reporta-se à noção de produção descrita por Lefebvre em suas obras, na qual este autor investe numa dupla determinação de produção: uma objetiva, voltada para produção de objetos, produtos, mercadorias e da produção do espaço como condição da reprodução da vida social; outra subjetiva, na qual o processo de subjetivação se dá pela linguagem e representação contida na produção do mundo da mercadoria.

Nasser e Fumagalli (1996, p. 25), não por acaso, afirmam que o objeto de investigação de Henri Lefebvre é o 'mundo às avessas' caracterizado pela destruição da natureza - inclusive humana -, pela crise das instituições políticas, esgotamento da religião [secularismo], separação inconciliável entre filosofia, ciência e arte, isolamento das ciências parcelares, emergências de novas necessidades sociais - como as urbanas - dentre outras que enfim levam ao aprisionamento da vida e a uma interpretação do mundo moderno em crise por uma filosofia de crise que passa ao largo da crítica, deixando de indicar a crise da sociedade, a qual não se encontra no econômico ou no político, mas nas próprias relações sociais [a crise ética e moral da sociedade que parece definir o século XXI], sendo necessário à sua análise, na visão lefebvriana, a inovação metodológica sob a perspectiva leninista do desenvolvimento desigual, na qual se explica que a crise atinge de modos diferentes 
os diferentes setores da prática social e, consequentemente, das diferentes sociedades.

Este artigo lança-se sobre a problemática da epistemologia da teoria da produção do espaço e seu rebatimento na fundamentação filosófica das Ciências Sociais. Nosso objetivo é traçar algumas notas acerca das bases epistemológicas da teoria da Produção do Espaço de Henri Lefebvre com relevo à sua significância à Geográfica. Especificamente, buscaremos apresentar a teoria mencionada, observar o contexto histórico no qual foi escrita, sua fundamentação teórica e o método sobre o qual foi construída.

A relevância desta pesquisa se dá pela contribuição a que se pretende na compreensão da importância do método e sua aplicação na construção do conhecimento científico a que se propõem os trabalhos acadêmicos. Ressalta-se, em particular, neste trabalho, a episteme da Produção do Espaço por ser o espaço um conceito caro à Geografia e o pensamento lefebvriano de grande relevância e influência dentre notáveis urbanistas, cientistas sociais e geógrafos dentro e fora da Europa, como David Harvey, José de Souza Martins, Ana Fani Carlos e o próprio Milton Santos. Os métodos e teoria propostos por Lefebvre, seja para aqueles que concordam, seja para aqueles que discordam de suas proposições, constituem referência para os estudos urbanos e perene debate às suas questões.

\section{MATERIAIS E MÉTODOS}

Partindo da leitura da obra intitulada La producción del espacio, do próprio Lefebvre, publicada originalmente em 1974, e de autores que nos ajudam a compreendê-la e explicitá-la no campo filosófico, teórico, empírico e metodológico, consoante a discussão que levantam acerca da episteme, do conceito de espaço e de sua produção capitalista, do urbano e da teoria em estudo, nossos procedimentos metodológicos consistem na revisão da literatura pertinente e de informações já publicadas e disponíveis em impressos ou meio eletrônico, recorrendo, principalmente, aos seguintes autores: Lefebvre (2013, 2016); Sposito (2004); Carlos (2016); Martins (1996); Santos (1985, 1996); Harvey (2004; 2005); (Corrêa, 2005); Schmidt (2012); Marconi e Lakatos (2010); Lorea (2013); Gutiérrez (2013); Gottdiener (1993); Soto (2013); Souza (2009) e Xavier (2013).

\section{SOBRE H. LEFEBVRE E O CONTEXTO DE SUA OBRA}

Figura 1. Henri Lefebvre (1971)

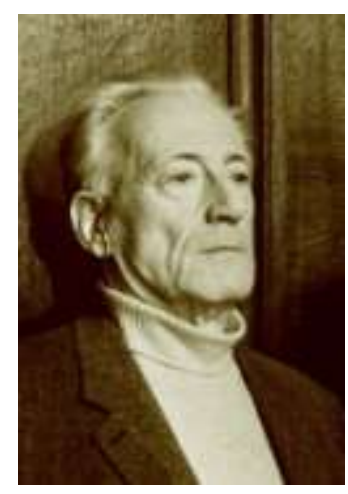

Fonte: Journal of Poetics Research ${ }^{1}$

Henri Lefebvre nasceu na região camponesa dos Pirineus, comuna francesa de Hagetmau, no departamento de Landes, na França de 1901. Assistiu praticamente todo o século $\mathrm{XX}$, participando ativamente dos debates que envolviam o campo político, econômico e social de seu país e do mundo de uma forma geral, morrendo aos 90 anos, no limiar do século XXI, em Navarrenx, França.

Filósofo e sociólogo, sempre de mente inquieta, Lefebvre também visitou os campos da matemática, linguística e da história e teve como influência as leituras que fez das obras de Marx,

Disponível em: http://poeticsresearch.com/article/6636/hibbard-henrilefebvre-1971-2/ 
Hegel, Nietzche, Engels, Lenin dentre tantas outras em sua extensa formação intelectual, sendo o seu maior desafio confesso inventar o novo (SOTO, 2013; HENRI... 2011). Firmou-se como um crítico inconteste do urbanismo funcionalista e da especialização espacial que, em sua visão, tende a liquidar a complexidade e a riqueza da vida urbana e interferir de modo sumário na práxis cotidiana. Foi debatedor do papel do Estado, da ciência e da técnica, das desigualdades sociais e das estratégias do neocapitalismo e, ao mesmo tempo, defensor da utopia concreta, a qual acreditava jogar luz sobre o real, formando parte, dando sentido e orientando o presente, fomentando o pensamento sobre um novo humanismo a partir da potência criadora e subversiva do espaço.

Nesse contexto, e sob as influências filosóficas mencionadas, Lefebvre publica, em 1974, uma de suas obras mais famosas com o título original La production de l'espace. Esta obra constitui-se no amadurecimento do seu pensamento acerca do urbano e da teoria sobre a produção do espaço num ciclo que tem início em 1968 com a publicação de O direito a cidade, perpassando pelos que se seguem: Do rural ao urbano e A revolução urbana (1970), O pensamento marxista e a cidade (1972) e Espaço e política (1972) (O direito à cidade II, 1973), assim elencados por Gutiérrez (2013).

Contudo, é na obra "A produção do Espaço" que Lefebvre aprofunda as suas ideias sobre o seu objeto de estudo neste ciclo - a condição urbana. Escrita na França dos trinta anos gloriosos, seu contexto é marcado pelas questões urbanas que já se revelavam com evidência através das transformações sociais e econômicas verificadas nos países desenvolvidos do pós-guerra, resultante da combinação da alta produtividade, com altos salários da classe média e alto consumo. Um panorama que pode ser entendido no contexto global sob o pano de fundo do ajuste espacial (espatial fix) e da acumulação via espoliação discutidos por David Harvey, respectivamente nas seguintes obras: A produção capitalista do espaço (2005) e O novo imperialismo (2004) e pelo desenvolvimento do próprio capitalismo.

Soto (2013) afirma que Henri Lefebvre, este autor que versa sobre a produção do espaço, o urbano e a cidade, foi um autor marginalizado pela academia, até mesmo entre os marxistas e esquerdistas, por adotar uma linha marxista não-ortodoxa, chegando, inclusive, a ser suspenso do partido comunista francês. Além disso, em sua teoria marxista do espaço, preocupava-se não só com o que é, mas com o que pode ser (o devir), instigando a crítica e o rótulo de historicista pelos estruturalistas, sobretudo althusserianos, segundo Gottidiener (1993). O modo pelo qual Lefebvre discutia o marxismo na modernidade e pelo qual entendia o espaço nessa perspectiva lhe custou muito preconceito em relação a sua obra, embora isso tenha mudado nos últimos tempos com o desponte de um interesse crescente sobre os seus trabalhos.

No Brasil, o sociólogo José de Souza Martins é apontado por Soto (2013) como o primeiro a introduzir Lefebvre neste país, sendo o seu maior estudioso e responsável pela interlocução qualificada deste autor francês no entendimento dos processos urbanos brasileiros. Apesar disso, admite-se que a obra de Lefebvre ainda é pouco conhecida, sendo que apenas uma pequena parte dela tem tradução para o português. Entretanto, sua influência atingiu vários urbanistas, historiadores, cientistas sociais e geógrafos brasileiros, incluindo Milton Santos, grande expoente da geografia brasileira, cuja inclinação lefebvriana é reconhecida em Gutiérrez (2013). Em todo o país, há, pelo menos, três grupos de pesquisas e de estudos lefebvrianos localizados especificamente na USP, UFMG e UFRN. Nesta última se encontra um esforço interdisciplinar para apreender as ideias lefebvristas 
aplicadas em pesquisas concentradas na área de arquitetura e urbanismo (SOTO, 2013).

A obra deixada por Lefebvre inclui mais de 70 livros que abrangem o marxismo no século $\mathrm{XX}$ e a condição urbana da sociedade moderna, onde a utopia urbana (concreta), a esperança se traduz nos espaços do possível a partir da intervenção dos cidadãos nesse espaço (urbano). Dentre esses livros e os já aqui citados estão: A Cidade do Capital; A Revolução Urbana; A Vida Cotidiana no Mundo Moderno; Lógica Formal/Lógica Dialética; Marxismo; O Vale de Capan (LIVRARIA CULTURA, 2017).

Por este momento, é bom que se diga que não há um ponto final que esteja presente na definição do autor Henri Lefebvre, mas, de fato, pode-se elencar no corpo das características que lhes cabem a atenção profunda à teoria, o apreço ao método científico, a competência na interpretação da realidade de seu tempo e espaço e sua inquietação pela compreensão do modo de vida nas cidades modernas.

\section{A TEORIA dA PRODUÇÃO DO ESPAÇO E SEUS FUNDAMENTOS}

"Que é um discurso teórico? $\mathrm{Na}$ sua significação mais geral é um discurso que tem por efeito o conhecimento de um objeto", afirma Althusser (1978, p. 15). O conhecimento pode ser entendido como o conjunto de informações que ajudam a compreender e explicar o mundo, incluindo princípios, premissas e hipóteses, atendendo a uma máxima de que não se produz conhecimentos fora da teoria. A despeito das diferenças entre Lefebvre e Althusser em relação ao método, a teoria é entendida como um sistema de conceitos científicos de base nos quais as "abstrações" carregam significativa importância em suas formulações. Escobar (1975, p. 7), ao citar Althusser, endossa que o que faz uma abstração ser científica é a sua referência a uma realidade concreta que existe mal ou bem, mas que não se pode 'tocá-la com as mãos', nem 'ver com os olhos'. Desse modo, todo conceito abstrato revela a existência do conhecimento de uma realidade que se dá a partir de uma prática teórica.

A prática teórica se caracteriza por um processo de transformação de uma matéria-prima específica- representações, noções, informações, categorias, conceitos - num produto específico, isto é, o conhecimento. A teoria na prática teórica se caracteriza por ser exatamente os meios de trabalho da transformação que esse processo de trabalho teórico efetua sobre uma matéria-prima ideológica. (ESCOBAR, 1975, p. 53).

Na teoria da Produção do Espaço de Henri Lefebvre, a prática teórica se pautou empiricamente na vida cotidiana, no Estado e no espaço urbano compreendidos através do pensamento marxista como ponto de partida. Dessa feita, ao publicar Espaço e política, Lefebvre lança a elaboração de uma teoria sobre a problemática do espaço, na qual entendia ser insuficiente definir o espaço a partir de sua vinculação à produção em sentido estrito dos economistas. $\mathrm{O}$ espaço de interesse lefebvriano seria, então, o espaço vivido, vinculado à prática social e sua problemática compreenderia um conjunto de problemas parciais que teria um traço comum: a espacialidade.

Dois blocos iniciais de questões são propostos por Lefebvre sobre os quais se desenvolve a sua teoria:

Quadro 1. Questões teóricas lefebvrianas

\begin{tabular}{|c|c|}
\hline $\mathbf{A}$ & B \\
\hline $\begin{array}{l}\text { i) Qual é o estatuto } \\
\text { teórico da noção de } \\
\text { espaço? }\end{array}$ & $\begin{array}{l}\text { i) Qual é a inserção do } \\
\text { espaço (representado, } \\
\text { elaborado, construído) na } \\
\text { prática social, econômica } \\
\text { ou política, industrial ou } \\
\text { urbana? }\end{array}$ \\
\hline $\begin{array}{l}\text { ii) Qual é a relação } \\
\text { entre o espaço mental e } \\
\text { o espaço social (espaço } \\
\text { da representação e a } \\
\text { representação } \\
\text { espaço)? }\end{array}$ & $\begin{array}{l}\text { ii) Onde e quando a } \\
\text { concepção do espaço atua } \\
e \text { quando ela se mostra } \\
\text { eficaze em quais limites? }\end{array}$ \\
\hline
\end{tabular}

Fonte: Elaboração própria com base em Lefebvre (2016, p. 40). 
Essas e outras questões vão compor as quatro hipóteses que este autor levanta acerca do espaço, quais sejam: a) $\mathrm{O}$ espaço é uma forma pura, transparente e inteligível (espaço matemático e filosófico); b) O espaço social é um produto da sociedade dependente da constatação empírica antes da teorização, resultante do trabalho e da divisão do trabalho (espaço funcional, objetivação do social e, por conseguinte, do mental); c) O espaço se coloca como racional-funcional, vinculado a reprodução da força de trabalho pelo consumo, a sociedade neocapitalista, um instrumento político intencional manipulado seja pelo Estado, classe dominante (a burguesia) ou grupo que represente a sociedade global ou local, como os tecnocratas; d) O espaço estaria essencialmente ligado à reprodução das relações sociais de produção, envolvendo a terceira hipótese numa análise mais profunda e diferenciada (espécie de esquema dinâmico comum às atividades diversas da cotidianidade, da mais simples às mais elaboradas na sociedade neocapitalista). Seria este "um espaço ao mesmo tempo abstrato-concreto, homogêneo e desarticulado, que se deveria reencontrar nas cidades novas, na pintura, na escultura e na arquitetura, e também no saber". (LEFEBVRE, 2016, p. 41 - 48).

No entanto, Lefebvre não está, de modo algum, preocupado em responder o que é espaço. Essa questão, em sua concepção, deve ser de interesse dos matemáticos/metafísicos, ao passo que a discussão pela qual se interessa se relaciona ao espaço vivido, por sua problemática representar:

[...] um aspecto importante e talvez essencial de um conhecimento da realidade urbana. Desse modo, a problemática do espaço pertence à teoria do urbano e à sua ciência e, por conseguinte, a uma problemática ainda mais vasta, a da sociedade global. Para nós, aqui, é um viés ou um front pelo qual se pode abordar um conjunto de questões. (ibidem, p. 41).

Ao problematizar o espaço, sob uma teoria do urbano e considerando um viés marxista, Lefebvre pondera sobre a ideia da vinculação da análise espacial às transformações da sociedade produzidas pelo esforço de acumulação de capital e pela luta de classes, o que aloca a análise espacial a uma expressão da estrutura social, deixando clara a interdependência das relações espaciais, e sobre a produção do espaço estar associada ao modo de produção [das mercadorias] da sociedade. Tais ponderações, noutro momento, podem ser consideradas a partir da interpretação de Clóvis de Barros Filho acerca do pensamento marxista:

\begin{abstract}
Marx acreditava que as explicações das ocorrências do mundo da vida se encontram camufladas, escondidas numa infraestrutura econômica. E assim, em qualquer sistema econômico considerado, é ali que você encontra as verdadeiras causas das ideologias, dos discursos, das dominações e de toda a produção humana. A consciência resulta da maneira como produzimos bens materiais numa determinada sociedade. (BARROS FILHO, 2015)
\end{abstract}

De Marx, Lefebvre herdou o pensamento de 8 que no espaço se desdobram as estruturas econômicas, políticas e ideológicas, porém, o espaço não seria apenas um receptáculo. Sua análise crítica do pensamento marxista o levou a uma visão de natureza multifacetada, mais ampla do que a simples redução a uma localização ou às relações sociais da posse de propriedade ou do processo de produção das coisas e do consumo (produção, consumo e troca). Desse modo, o espaço seria um bem imóvel, localizado fisicamente, mas também uma liberdade existencial e uma expressão mental, sendo ao mesmo tempo o local geográfico da ação e a possibilidade social de engajarse na ação. Ideia fundamental para a noção de práxis lefebvriana.

Assim, se na teoria da economia política tradicional marxista o espaço aparece reduzido a três domínios: produção, consumo e troca, ou seja, visto apenas como espaço da ação, um meio de produção tal qual o capital e o trabalho, Gottidiener (1993, p. 127) 
expressa que, em sua teoria, Lefebvre propõe que esses três domínios, quando considerados em conjunto como espaço social, podem constituir o quarto domínio de relações sociais, qual seja: a produção de riqueza ou mais-valia, o que faz desse espaço, ele próprio, também um elemento das forças produtivas da sociedade, sobretudo através da atuação da forma e do design.

Na obra de 1974, Lefebvre evoca o espaço numa categoria superior à da cidade, revalorizando-o na teoria social de base hegeliana do grupo de sua ala esquerdista, no qual se alocavam David Friedrich Strauss, Edgar e Bruno Bauer, Feuerbach e Ciszkowski, e no pensamento marxista, numa abordagem que privilegia o tempo. Para Marcuse (2004, p. 220),

[...] Hegel foi o último a interpretar o mundo como razão, a sujeitar a natureza e a história aos critérios do pensamento e da liberdade. Ao mesmo tempo, ele identificou a ordem política e social efetuada pelos homens com a base sobre que se devia realizar a razão. Seu sistema trouxe a filosofia ao limiar da negação da filosofia, constituindo por isso o único elo entre as formas velha e nova da teoria crítica, entre a filosofia e a teoria social.

O pensamento hegeliano não influenciou Lefebvre apenas em sua própria teoria social sobre o espaço, mas também na dialética que está presente em Marx e, por conseguinte, no conjunto da obra lefebvriana como possibilidade de interpretação e reinvenção do método de sua análise socioespacias. Sua teoria unitária do espaço, que reúne as instâncias física, mental e social, expõe o mesmo como um produto social resultado das ações, práticas, relações e experiências sociais e, ao mesmo tempo, fazendo parte delas. Desse modo, enquanto produto, o espaço é passível de consumo e utilização. Contudo, não pode ser comparado a outros ou quaisquer objetos produzidos, tendo em vista que o espaço intervém na produção, ou seja, é suporte, mas também campo de ação social, o que significa que não há relação social sem espaço, nem espaço sem relação social. Assim, a resultante espaço social predispõe um conceito que se desenvolve da seguinte forma:

O conceito de espaço social desenvolve mediante sua ampliação. Se introduz no seio do conceito de produção, o invade, inclusive, chegando a fazer parte (quiçá uma parte essencial) de seu conteúdo. Daí engendra um movimento dialético muito específico que não abole certamente a relação <<produção-consumo〉> aplicada as coisas (bens, mercadorias, objetos de troca), mas que modifica mediante sua ampliação. (LEFEBVRE, [1974] 2013, p. 141. Tradução nossa).

Nessa perspectiva, Lefebvre ressalta que cada sociedade produz seu espaço (social). Numa sociedade capitalista a cidade se sobressai iniciando um processo de urbanização da sociedade que carrega consigo as características do sistema político, social e econômico que a constitui, que, neste caso, é permeado por contradições. Desaparece a cidade tradicional como objeto e concepção, mas sua essência - o urbano - persiste. O urbano, em sua visão, é entendido como processo, horizonte e prática e, nesse contexto, o espaço produzido pelas relações sociais capitalistas é fragmentado e homogêneo, preponderantemente abstrato e instrumental.

Diante dos discursos acerca desse novo espaço, aferidos por ciências fragmentárias, Lefebvre avança em sua teoria unitária para superar as relações analíticas dicotômicas que levam à confusão das interpretações acerca do espaço e busca uma síntese no estilo hegeliano, a partir da elaboração de uma tríade conceitual composta por três dimensões e três espaços respectivos abstraídos por determinadas condições, definidos nos seguintes moldes: 
Quadro 2: A tríade do espaço lefebvriano

\begin{tabular}{|c|c|c|}
\hline Dimensões & Espaços & $\begin{array}{l}\text { Condição de } \\
\text { abstração }\end{array}$ \\
\hline $\begin{array}{l}\text { Práticas } \\
\text { Espaciais }\end{array}$ & $\begin{array}{l}\text { Espaço } \\
\text { Percebido }\end{array}$ & $\begin{array}{l}\text { Experiência } \\
\text { material que } \\
\text { vincula } \\
\text { realidade } \\
\text { cotidiana } \\
\text { realidade } \\
\text { urbana, } \\
\text { englobando } \\
\text { tanto a produção } \\
\text { como a } \\
\text { reprodução } \\
\text { social (tempo, } \\
\text { redes e fluxos } \\
\text { materiais } \\
\text { imateriais) }\end{array}$ \\
\hline $\begin{array}{l}\text { Representações } \\
\text { do Espaço }\end{array}$ & $\begin{array}{l}\text { Espaço } \\
\text { Concebido }\end{array}$ & $\begin{array}{l}\text { Especialistas } \\
\text { (engenheiros, } \\
\text { arquitetos), } \\
\text { políticos, } \\
\text { planejadores e } \\
\text { "cientistas" } \\
\text { urbanos que } \\
\text { criam signos e } \\
\text { códigos de } \\
\text { ordenação que } \\
\text { fragmentam e } \\
\text { restringem o } \\
\text { espaço. }\end{array}$ \\
\hline $\begin{array}{l}\text { Espaços de } \\
\text { Representação }\end{array}$ & $\begin{array}{l}\text { Espaço } \\
\text { Vivido }\end{array}$ & $\begin{array}{l}\text { A imaginação e } \\
\text { o simbólico dos } \\
\text { usuários e } \\
\text { habitantes que } \\
\text { conduz a novas } \\
\text { possibilidades } \\
\text { da realidade } \\
\text { espacial. }\end{array}$ \\
\hline
\end{tabular}

Fonte: Elaboração própria com base em Lorea (2013).

Da interpretação do quadro 2, ousa-se alocar o espaço concebido, que compreende a representações do espaço, como o espaço oficial de comando da sociedade, uma vez que Lefebvre (2013) enxerga a tensão (trialética) que existe entre os três tipos de espaço que propõe, evocando a potencialidade das representações do espaço sobre o espaço percebido e vivido. São as representações do espaço, ou seja, o espaço concebido, que tangencia os horários, nível de contato entre os indivíduos do sistema urbano e forma redes sociais que agregam ou segregam grupos sociais consoantes os fluxos de pessoas, produtos, serviços e dinheiro (renda) que ali circulam, ou que "podem" circular.
Nesse contexto, Schmid (2012) entende que Lefebvre desenvolveu um conceito específico de dialética, original e independente, constituindo-se numa tríade teórica que tem em sua base Marx, Hegel e Nietzche. Na Teoria da Produção do Espaço aqui tratada, Schmid ainda aponta que o conceito relacional de espaço e tempo de Lefebvre permite que o espaço represente a ordem sincrônica da realidade social e o tempo, por outro lado, a ordem diacrônica, assim desenhando o processo histórico da produção social do espaço.

Em suma, para Lefebvre, o espaço só pode ser apreendido dialeticamente, pois constitui uma abstração concreta, sendo que a principal contradição espacial da sociedade é a confrontação entre espaço abstrato (exteriorização de práticas econômicas e políticas que se originam com a classe capitalista e com o Estado) e o espaço social (espaço de valores de uso produzidos pela complexa interação de todas as classes na vivência diária). Então, sua importância é conquistada pela dialética entre o valor de uso e o valor de troca, que produz tanto um espaço social de usos quanto um espaço abstrato de expropriação. Portanto, entender este espaço exige a compreensão de como ele é produzido como abstração concreta multifacetada (GOTTIDIENER, 1993, p. 131-132). Assim, a dialética se constitui o método indispensável à compreensão do espaço para Lefebvre, sendo esta dialética um retorno a Marx, o que difere, no dizer de José de Souza Martins, de ir a Marx:

Lefebvre não retorna, simplesmente, aos conceitos de Marx, mas à relação entre um modo de pensar e uma prática, isto é, a um projeto na práxis que define o trajeto de uma vida. $\mathrm{O}$ método dialético está no centro desse retorno. Mas o método que se foi definido ao longo da obra de Marx, que combina os momentos do método de investigação e do método de explicação; e que culmina com a análise inacabada sobre as classes sociais, isto é, sobre a primeira tríade: trabalho, terra e capital, ou seja, salário, renda e lucro. O pensamento de Marx não era binário, como o fez mais tarde o marxismo vulgar, e sim triádico (MARTINS, 1996, p. 14). 
A tríade lefebvriana considera três momentos dialeticamente interconectados: a prática social material de Marx; a linguagem e pensamento hegeliano; e o ato criativo, poético de Nietzsche, o qual também perpassa pela linguagem, conforme Schmid (2012), constituindo, assim, uma complexa dialética socioespacial.

\section{O MÉTODO}

Segundo o Dicionário online de Português (2016), a palavra "método", em seu sentido denotativo, significa "Técnica; modo usado para realizar alguma coisa: método científico"; e, em seu sentido figurado pode ser descrito como "Reunião dos meios através dos quais é possível alcançar um objetivo". A questão do método para o conhecimento científico é fundamental à sua veracidade, a despeito da fragmentação das disciplinas. O método é um "instrumento intelectual e racional que possibilita a apreensão da realidade objetiva pelo investigador, quando este pretende fazer uma leitura dessa realidade e estabelecer verdades científicas para a sua interpretação" (SPOSITO, 2004, p. 23).

A leitura da realidade é dada sobre o espaço, que, não raramente, é feita pela sua fragmentação, tal qual se fragmenta a leitura do próprio espaço. Para Corrêa (2005, p. 145) "O arranjo espacial da fragmentação pode variar mas ela é inevitável”. Em sua visão isso está relacionado a uma das características do espaço urbano, a de ser simultaneamente fragmentado e articulado, reflexo e condição social, também campo simbólico e de lutas. Esse quadro permite, em especial ao geógrafo, diferentes análises, privilegiando uma ou outra dessas características, sem excluir qualquer delas. Para este autor, fragmentação e articulação são características complementares e que é pela articulação que o espaço ganha unidade. Nesses termos, Santos (1985) propõe que o espaço deva ser considerado em sua totalidade, o que para este autor isto é uma questão de método. $\mathrm{O}$ método, enquanto construção de um sistema intelectual seria, então, fundamental na abordagem da realidade, a qual advém de uma construção social, conforme Santos (1996).

Mas, que método seria esse? Sposito (2004) classifica apenas três únicos métodos científicos, a saber: hipotético-dedutivo, fenomenológico e dialético por estes apresentarem características como leis e categorias e estarem historicamente relacionados a procedimentos específicos e teorias disseminadas pela comunidade científica; sendo seus elementos a doutrina, a teoria, as leis, os conceitos e as categorias.

Em consonância com Sposito é a afirmação de Marconi e Lakatos (2010, p.65): "não há ciência sem o emprego de métodos científicos". Contudo, para Pedro Demo (1989, p. 16) “o maior problema da ciência não é o método, mas a realidade [...]. Dependendo da concepção de realidade social, vai variar o método de captação, que é logicamente posterior." Assim, se para Demo (1989) há, especificamente, metodologia científica em ciências sociais, para Marconi e Lakatos (op. cit.) há métodos específicos das ciências sociais. Estas autoras afirmam existir uma clara distinção entre "o método" e "os métodos". O primeiro se caracterizaria por ter uma abordagem mais ampla, com um nível de abstração mais elevado sobre os fenômenos da natureza e da sociedade, seria, então o método de abordagem. O segundo refere-se aos "métodos de procedimento", etapas mais concretas da investigação, voltadas para uma explicação geral dos fenômenos de forma mais restrita, mais técnica, aqui se entende como o modo operacional de fazer. Dentre esses métodos, as autoras citam o método histórico, o comparativo, o estatístico, o funcionalista, o estruturalista e outros. "Diferenciando-se do método de abordagem, os métodos de procedimento muitas vezes são utilizados em conjunto, com a finalidade de obter vários 
enfoques do objeto de estudo" (MARCONI e LAKATOS, 2010, p. 95).

Seguindo o discurso de Marconi e Lakatos, depreende-se que, do ponto de vista do método, são dois os que se destacam na construção da teoria do espaço lefebvriano: o método de abordagem dialético e o método de procedimento regressivo-progressivo.

O método dialético perpassa por toda a obra lefebvriana, com destaque para sua inovação na própria abordagem dialética ao constituir uma interpretação trialética, considerando três momentos dialeticamente interconectados: a prática social material de Marx; a linguagem e pensamento hegeliano; e o ato criativo, poético de Nietzsche, o qual também perpassa pela linguagem, conforme Schmid (2012), constituindo, assim, uma complexa dialética socioespacial. Sobre a dialética que o embasou, Lefebvre (2013, p. 329) escreve que:

De Heráclito a Hegel e Marx, el pensamiento dialéctico se liga estrechamente al tempo; las contradicciones dicen o expresan las fuerzas y las relaciones de fuerzas que se enfrentan en una historia (en la historia en general)."

Entendendo que "A transição de Hegel a Marx é, sob todos os aspectos, uma transição a uma ordem de verdade essencialmente diferente que não se presta a ser interpretada em termos filosóficos" (MARCUSE, 2004, p. 225), a interpretação de Lefebvre a dialética de Hegel e Marx, associada a de Nietzche resultou nessa proposta de análise socioespacial que, não dogmática, sugere um pensamento novo, sem desprezar o velho, mas contextual ao momento histórico e material vivido por Lefebvre, na qual o tempo constitui um fator primordial. Nesse novo pensamento incluem-se, entre outras, as dualidades entre valor de uso $\mathrm{x}$ valor de troca; relações de dominação x relações libertárias; realidade material $\mathrm{x}$ propriedade formal.

Gottidiener (1993) compreende que em sua teoria, Lefebvre eleva a "práxis espacial" a uma atividade radical ao lado de esforços para organizar as relações sociais, enquanto sustenta sua perspectiva com uma teoria marxista do espaço. É o seu olhar pessoal que empresta a dialética que criou uma característica própria e inusitada centrada na condição urbana.

Nesses termos, a condição urbana, ligada as relações sociais que se passam no espaço, é analisada a partir da premissa de que o espaço é produzido historicamente pelo homem através da organização política e econômica de sua sociedade, o que coloca o espaço como expressão, mas também condicionante da atuação das relações conflitantes entre capital e trabalho e embasa a modificação na relação homemnatureza.

Para estudar a (nova) relação homem-natureza pelo viés marxista, mas compreendida no tempo e no espaço da modernidade, Lefebvre lança mão de um procedimento investigativo específico para realidade social que é o método regressivo-progressivo, no qual compreende três momentos distintos: a descrição do visível, a análise regressiva e a progressão genética. Onde a descrição do visível constitui um expediente para obter informações sobre a diversidade socioespacial do objeto de estudo; a análise regressiva seria uma decomposição da realidade na tentativa de datar exatamente cada relação social revelada; e a progressão genética, denominada especificamente de histórico-genética, consiste no reencontro com um presente elucidado, compreendido e explicado (SOUZA, 2009; XAVIER, 2013).

Desse modo, no plano de sua obra, A Produção do Espaço, Lefebvre assim apresenta seu estudo conforme o método regressivo-progressivo que adotou:

[...] Resumamos el plan del libro, inherente al enfoque seguido: un estudio <retro> del espacio social en su historia y génesis, a partir del presente se remonta hacia esta génesis para después regressar sobre o actual, lo que permite entrever, si no prever, lo posible y el futuro. Este procedimiento deja lugar a estudios locales, en 
diferentes escalas, insertándolos en un análisis general, en la teoria global. (LEFEBVRE, [1985] 2013, p. 58).

Percebe-se que este autor ao tratar do espaço social ou de seus processos, recorre à história, procedimento que, segundo Xavier (2013), foi adotado desde quando Lefebvre trabalhava em sua tese de doutorado sobre os moradores dos montes Pirenaicos (região onde ele nasceu) e encontrou dificuldades no estudo de seu objeto em virtude das transformações do modo de vida nos Pirineus em consequência do processo de industrialização. A partir daí, Lefebvre apreende que o tempo é um elemento fundamental para a descrição dos fatos e, por conseguinte, entendimento do presente, tendo em vista a metamorfose pela qual o objeto analisado se submete no transcorrer do tempo. Nessa perspectiva, a história e o seu materialismo passam a serem parâmetros cruciais na aplicação e desenvolvimento do seu método (regressivo-progressivo), o qual foi reconhecido e elogiado, inclusive, por Jean Paul Sartre, com quem polemizou boa parte de sua vida.

Por fim, é importante destacar que ambos os métodos, dialético e progressivo-regressivo, configuram uma característica ímpar na teoria da produção do espaço de Henri Lefebvre, sem a qual seu trabalho não seria o que é: um clássico que envelhece bem, no dizer de Lorea (2013) e que permitiu a este autor realizar uma abordagem marxista do espaço extremamente diferente da formulada por seus contemporâneos, sem, no entanto, refutar a teoria da economia política, observando que os conflitos sociais não se davam apenas pelo viés das relações de produção, mas também pelo espaço (social), trazendo à baila o valor de uso para discussão e o espaço enquanto elemento das forças produtivas, tudo isso vinculado ao tempo que, para Lefebvre, tem valor de uso fundamental.

O pensamento lefebvriano, na visão de Calos (2016, p. 54), constitui um dos caminhos pelos quais se pode pensar a Geografia, uma orientação teóricometodológica a partir da qual é possível construir uma 'análise da realidade' conduzida, inclusive, pelo prolongamento do pensamento marxista-lefebvriano ${ }^{2}$ como movimento de superação a partir da Geografia.

\section{CONCLUSÃO}

Da leitura de A produção do espaço, espécie de síntese, no sentido de uma produção mais madura acerca de toda a obra escrita sobre a cidade, o espaço e o urbano, infere-se que seu autor buscou, através do seu método e métodos de procedimento, construir um projeto de conhecimento ao mesmo tempo descritivo, analítico e global que redundasse numa teoria sobre a produção do espaço urbano. Uma teoria crítica, não da sociedade ou da época, mas das implicações, imbricações e contradições da produção do espaço no momento estudado, baseada principalmente em Marx, Hegel e Nietzsche.

O momento em que Lefebvre se debruça sobre a obra de 1974 é marcado pelo tempo contido em certos debates políticos e intelectuais inscritos na França da produção de seus textos, isso se reflete em suas preocupações e perguntas de partida. Nesses termos, depreende-se que sua preocupação maior não era o método, mas a interpretação da realidade que queria abarcar, o que não significa uma despreocupação com o conhecimento científico. Ao contrário, tendo em vista que para alcançar essa realidade Lefebvre investiu em dois métodos que podem ser considerados próprios, dois caminhos que deixaram um importante legado às ciências sociais: a sua dialética triádica e o método regressivoprogressivo. Seu compromisso com a ciência e o conhecimento dela derivado se revela em suas bases

2 Ana Fani Carlos (2016) faz menção a um horizonte geográfico aberto pelas obras de Karl Marx e Henri Lefebvre, que na interpretação de Maurício de Abreu seria denominado de "abordagem marxista-lefebvriana". 
filosóficas e sua legitimidade em acompanhá-las, opor-se a elas ou complementá-las, mas sempre com o cuidado de apontar as contradições impostas e os caminhos seguidos na busca pela compreensão da produção do espaço que naquele momento se descortinava à sua frente.

Sobre o propósito da sua obra, Lefebvre ([1974] 2013) afirma que não pretende elaborar uma teoria crítica do espaço existente que substitua as descrições e recortes que conformam este espaço, nem substituí-lo por outras teorias críticas da sociedade em geral. Seu objetivo, a propósito do espaço, é promover a confrontação entre as ideias e proposições que esclarecem o mundo moderno. Aconselha o autor ao leitor, a tomar as proposições de sua obra não como teses ou hipóteses isoladas, como pensamentos que depois são escrutinados, mas como prefigurações situadas no limiar da modernidade.

Avesso às ciências parcelares, a discussão marxista ortodoxa e a qualquer tipo de pensamento dogmático; aderente a uma nova perspectiva - a metafilosofia, e defensor aguerrido da teoria como degrau do conhecimento, Henri Lefebvre morre em 1991 deixando um legado não de modelos teóricos e/ou programas de desenvolvimento, mas de possibilidades de se estudar o urbano, compreendendo-o em sua diversidade e peculiaridades, opondo-se sempre a imobilidade da teoria, valorizando, sobretudo, o espaço vivido em relação ao concebido.

A autora declarara não haver qualquer potencial conflito de interesses referente a este artigo.

\section{REFERÊNCIAS}

ALTHUSSER, Louis. Sobre o trabalho teórico 2ed. Porto: Presença Ltda, 1978.

BARROS FILHO, Clóvis de. 2015. Por que ler Marx? Centro de debates e disseminação de conhecimento de São Paulo e Rio de Janeiro Casa do Saber. Disponível
https://www.youtube.com/watch?v=m93ihiODIgE\&fe ature=youtu.be. Acesso em: 06/01/2017.

CARLOS, Ana Fani Alessandri. Da "organização" à "produção" do espaço no movimento do pensamento geográfico. p. 53 - 73. In: CARLOS, Ana Fani Alessandri; SOUZA, Marcelo Lopes de; SPOSITO, Maria da Encarnação Beltrão (Orgs.). A produção do espaço urbano: agentes e processos, escalas e desafios. 1ed.,4.reimpr. São Paulo: Contexto, 2016.

CONCEITO. de: conceito de epistemologia. conceito de epistemologia. 2013. Disponível em: http://conceito.de/epistemologia. Acesso em: 1 mar. 2017.

CORRÊA, Roberto Lobato. O espaço urbano: notas teórico-metodológicas. p. 145-152. In:

Trajetórias geográficas. 3ed. Rio de Janeiro: Bertrand Brasil, 2005.

DEMO, Pedro. Metodologia científica em ciências sociais. 2 ed. Ver. e ampl. São Paulo: Atlas, 1989.

DICIONÁRIO online de português. 2016. Significado de método. Disponível em: https://www.dicio.com.br/metodo/. Acesso em: 22/12/2016.

GOTTDIENER, Mark. A produção social do espaço urbano. Tradução de Geraldo Gerson de Souza. São Paulo: USP, 1993. (Título original: The social production of urban sapce, 1985).

GUTIÉRREZ, Emilio Martínez. Introducción: Ciudad, espacio y cotidianidad en el pensamiento de Henri Lefebvre. p. 29-50. In: LEFEBVRE, Henri. La producción del espacio. Tradução de: Emilio Martínez Gutiérrez. Espanha: Capitan Swing, 2013. (Título original: La production de l'espace, 1974).

HARVEY, David. A acumulação via espoliação. p. 115-148. In: - O novo imperialismo. São Paulo: Edições Loyola, 2004 (Livro publicado originalmente em 2003).

HARVEY, David. O ajuste espacial: Hegel, Von Thunen e Marx. p. 95-126. In: A produção capitalista do espaço. São Paulo: Annablume, 2005 (Livro publicado originalmente em 2001).

HENRI Lefebvre. 2011. Disponível em: http://henrilefebvre.blogspot.com.br/2011/11/henrilefebvre_12.html. Acesso em: 02/01/2017.

LEFEBVRE, Henri. La producción del espacio. Tradução de: Emilio Martínez Gutiérrez Espanha: Capitan Swing, 2013. (Título original: La production de l'espace, 1974). 
LEFEBVRE, Henri. O espaço. p. 37-55. In:__. Espaço e política: o direito à cidade II. 2 . ed. Belo Horizonte: UFMG, 2016. (Seminários sobre o Espaço, realizado em Nanterre, Oxford etc, em 1972).

LIVRARIA CULTURA. 2017. Henri Lefebvre. São Paulo. Disponível em: http://www.livrariacultura.com.br/e/henri-lefebvre30053. Acesso em: 04/01/2017.

LOREA, Ion Martínez. Prólogo: Henri Lefebvre y los espacios de lo posible. p. 9-28. In: LEFEBVRE, Henri. La producción del espacio. Tradução de: Emilio Martínez Gutiérrez. Espanha: Capitan Swing, 2013 (Título original: La production de l'espace, 1974).

MARCONI, Marina de Andrade; LAKATOS, Eva Maria. Fundamentos de metodologia científica. 7ed. São Paulo: Atlas S.A., 2010.

MARCUSE, Herbert. Razão e revolução: Hegel e o advento da teoria social. 5ed. Tradução de Marília Barroso. São Paulo: Paz e Terra, 2004.

MARTINS, José de Souza. As temporalidades da História na dialética de Lefebvre. p. 13-23. In:

(Org.). Henri Lefebvre e o retorno à dialética. São Paulo: Hucitec, 1996.

NASSER, Ana Cristina Arantes; FUMAGALLI, Marlene. A opressão da equivalência, as diferenças. p. 25-37. In: MARTINS, José de Souza (Org.). Henri Lefebvre e o retorno à dialética. São Paulo: Hucitec, 1996.

SPOSITO, Eliseu Savério. Geografia e filosofia: contribuição para o ensino do pensamento geográfico. 5 reimp. São Paulo: UNESP, 2004.

SANTOS, Milton (Org.) Novos rumos da geografia brasileira. São Paulo: Hucitec, 1996.

SANTOS, Milton. Espaço e método. São Paulo: Nobel, 1985.

SOTO, William Héctor Gómes. 2013. O pensamento crítico de Henri Lefebvre. Revista Espaço Acadêmico, ano XII, no 140 , publicação mensal, Jan. Disponível em: http://www.periodicos.uem.br/ojs/index.php/EspacoA cademico/article/view/17379. Acesso em: 02//01/2017.

SOUZA, Charles Benedito Gemaque. 2009. A contribuição de Henri Lefebvre para reflexão do espaço urbano da Amazônia. Revista Confins, $n^{\circ} 5$, mai. Disponível em: http://confins.revues.org/5633. Acesso em: 04/01/2017.

XAVIER, Glauber Lopes. Ciência e método: o pensamento marxista de Henri Lefebvre. 2013. Revista Eletrônica de Ciências Sociais, ano 7, ed. 16, jun./set. Disponível em: https://csonline.ufjf.emnuvens.com.br/csonline/article/ viewFile/2651/1624. Acesso em: 08/01/2017. 